\title{
PRIMERAS CULTURAS JUVENILES EN CHILE: PÁNICO, MALONES, POLOLEO Y MATINÉ ${ }^{1}$
}

\author{
FIRST YOUTH CULTURES IN CHILE: PANIC, MALONES, \\ POLOLEO AND MATINÉ
}

\section{YANKO GONZÁLEZ²}

\section{RESUMEN}

Este trabajo aborda la constitución de las primeras culturas juveniles surgidas en Chile a partir de la segunda mitad de la década de 1950. A través del análisis de fuentes orales -historias de vida-, documentales, teóricas e históricas, planteamos que dichos colectivos fueron modelados tanto por procesos de apropiación activa de la emergente industria cultural segmentada, como por el etiquetaje y pánico moral generado por la prensa escrita. A su vez, sostenemos que la génesis de dichas culturas juveniles -particularmente Carlotos- se configura como una metáfora de las transformaciones modernizadoras desiguales ocurridas en el país a mediados del siglo pasado. Consecuentemente, proponemos que estos primeros indicios de tribalización juvenil expresan las mutaciones ocurridas tanto en las relaciones intergeneracionales como en las del propio sujeto juvenil, que transita de manera extensiva de la condición de soltera/o a la de joven, a partir de espacios y prácticas diferenciales en relación a la sociedad adulta, como el noviazgo informal ("pololeo"), las fiestas domésticas cooperativas ("malones") y la asistencia segregada a funciones cinematográficas ("matinés").

Palabras clave: Chile, historia de la juventud, primeras culturas juveniles, Carlotos.

\section{ABSTRACT}

This work deals with the constitution of the first youth cultures in Chile which emerged during the second half of the 1950's. Through the analysis of oral sources -life histories-, documental, theoretical and historical, we claim that these groups were

${ }^{1}$ Este trabajo forma parte de los resultados del proyecto Fondecyt No 11075007. El autor agradece la valiosa colaboración de colegas, amigos e informantes para emprender este trabajo, en especial a Cecilia Baeza, Cristián Sepúlveda, Leonardo Piña, Alejandra Cornejo y Soledad Alarcón.

${ }^{2}$ Doctor en Antropología, Instituto de Ciencias Sociales, Universidad Austral de Chile, Casilla 567, Valdivia, Chile. E-mail: ygonzale@uach.cl 
modelled as much by processes of active appropriation of an emergent and segmented cultural industry as by labelling and moral panic generated by the written press. At the same time, we believe that the genesis of these youth cultures -particularly the so called Carlotos- can seen as a metaphor of the unequal modernising transformations that took place in Chile in the middle of the last century. Consequently, we propose that these first signs of youth tribalization express the mutations that occurred in intergenerational relations as well as in the subjectivity of young people, passing in an extensive manner from the condition of being single to that of youth, due to specific differential spaces and practices in relation to adult society, including dating ("pololeo"), cooperative domestic celebrations ("malones") and segregated attendance at cinema showings ("matinés").

Keywords: Chile, History of youth, First youth cultures, Carlotos.

Recibido: 17.03.10. Aceptado: 25.09.10.

\section{INTRODUCCIÓN}

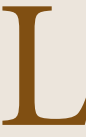

AS TEORÍAS y aproximaciones histórico-culturales a las y los jóvenes se han elaborado de sobremanera a partir de fuentes centroeuropeas y anglosajonas. Aun cuando en América Latina y particularmente en Chile dichas aproximaciones han tenido un progresivo desarrollo (v.gr. Salazar y Pinto, 2002; Caccia Bava, Feixa y González, 2004; Feixa y González, 2005), el grueso de las investigaciones han abordado sólo algunos aspectos y momentos del desarrollo del sujeto juvenil, soslayando un conjunto de actores, procesos y dimensiones -fundamentalmente identitarias, simbólicas y microhistóricas-, en la dialéctica y, principalmente, en la diacronía de estos colectivos en Chile. De este modo, resulta paradójico que mientras los estudios sobre culturas juveniles a nivel sincrónico -etnográfico, por ejemplo- se multiplican, las aproximaciones histórico-culturales tengan escaso desarrollo o se centren eminentemente en el período postautoritario -1990 en adelante- (v. gr. Zarzuri y Ganter, 2005).

La década de los '50 y, especialmente la del '60, marcaron un hito en la visibilización total y protagonismo preferente de los sujetos juveniles, traducidos rápidamente como grupo de interés, de presión, de "poder" como diría Mattelart \& Mattelart en los '70 (1970: 10)-, incluso, de "nuevo proletariado" (Hermann, 1968: 127). Décadas que expresaron el paso de una cultura "cofigurativa" a una "prefigurativa" según Mead (1990), en la que los pares reemplazan a los padres como referentes para la construcción del presente sociocultural, instaurando una ruptura generacional sin parangón en la historia. La aparición de culturas juveniles implicó una mayor complejidad, densidad y autonomía del marcador biológico (edad) y gene- 
racional de las y los jóvenes con respecto al mundo adulto. De esta forma comienzan a proliferar en las urbes metropolitanas colectivos de jóvenes aglutinados en microsociedades que, corporeizados por la clase, la etnicidad, el territorio y la estética (Feixa, 1999), son creados y recreados por los medios de comunicación masiva (la industria cultural segmentada) y el mercado.

Las condiciones de producción de las culturas juveniles chilenas están marcadas por la paulatina modernización de la esfera material que, sustentada en gran medida por el Estado Desarrollista y Populista y el éxito económico norteamericano después de la II Guerra -traspasado a América Latina desde 1961 a través de la "Alianza para el Progreso"-, posibilitarán la extensión de la electricidad, la urbanización, la expansión de la matrícula educativa, la industrialización y la migración campo-ciudad. En efecto, desde mediados de siglo, la sociedad chilena venía sumando cambios acelerados, que terminaron por modificar radicalmente su estructura social. Se manifiesta una precipitada urbanización y un sostenido crecimiento demográfico debido a un aumento de la natalidad y una baja de la mortalidad. En este contexto, comienza a emerger una mayoría "biológicamente" joven: sólo al comenzar la década del ' 60 el 49,4\% de la población era menor de 20 años, según cálculos de la CEPAL/UNICEF en 1967 (Gurrieri, Torres-Rivas et al., 1971: 17). Junto a ello, se presenta a partir de 1952 un incremento sin parangón del estudiantado secundario y superior: el número de alumnos universitarios que en el año 1952 era de 9.335, para 1957 esta cantidad sube a 20.440 y en 1965 a 41.801 (González, 2004a).

No obstante, es la "modernización" de la esfera simbólica la que tiene un impacto capital en la constitución de estas culturas juveniles, fenómeno atribuido habitualmente a la influencia externa (la norteamericanización de las costumbres vía la aparición y expansión de la industria cultural) o al agotamiento de las formas sociales burguesas criollas. Cambios en la esfera cultural que, ciertamente, son tributarios de la transnacionalización del mercado simbólico en América Latina y la reproducción de la industria cultural del primer mundo a nivel local (cf. Brunner, Barrios y Catalán, 1989; Brunner, 1988 y García Canclini, 1990).

Desde fines de la década de 1950, tanto la industria cultural como las comunicaciones crecen progresivamente en Chile. En este sentido, la llamada "sociedad de la abundancia" norteamericana impactó radicalmente la vida social y al sujeto joven de la región: surgimiento de un inédito mercado juvenil masivo -teenage market-: películas, periodismo juvenil, industria cinematográfica y musical segmentada -el rock and roll irrumpe con toda 
su fuerza-, junto con toda una serie de productos asociados, desde transistores, discos, tocadiscos y motocicletas, hasta objetos fetiches de diverso tipo. La personificación de este momento se encuentra en el surgimiento de varios ídolos musicales y cinematográficos, cuyas imágenes se desterritorializan rápidamente a partir de las tecnologías comunicativas recién estrenadas: Marlon Brando, James Dean y Elvis Presley, encarnaciones matrices de las culturas juveniles en los EE.UU. No obstante, como veremos, este proceso en Chile y América Latina es paulatino y diferencial. Las transformaciones estructurales que se sucederán en el país y que posibilitarán nuevas adscripciones identitarias en las y los jóvenes se incuban lenta y segmentadamente desde la segunda mitad de la década de 1950. Ello debido a las profundas desigualdades del proceso y modelo modernizador, que esconde en su aggiornamento importantes niveles de exclusión social y económica en la población juvenil.

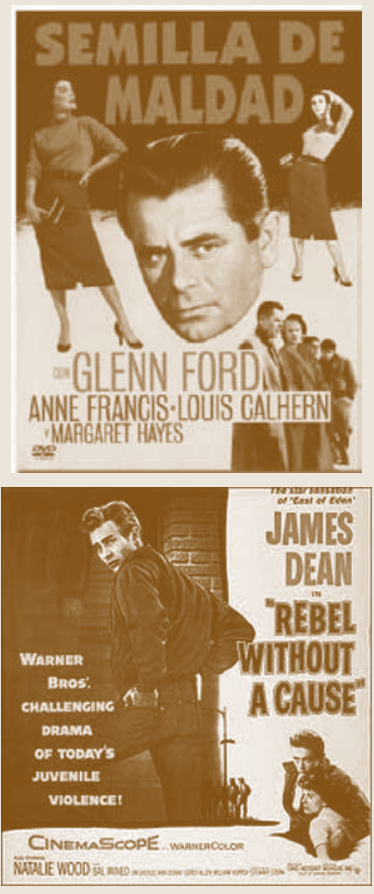

\section{PÁNICO MORAL: COLÉRICOS Y CARLOTOS}

El mismo año en que se estrena la película Blackboard Jungle (1955) -en Chile rotulada como Semilla de maldad-aparece Rebel Without a Cause, donde Jim Stark (James Dean) en un "exilio interior" se enfrenta a un grupo de compañeros que no lo comprende y al mismo tiempo lidia con sus padres en "un universo regido por los adultos y en el que los adultos dimitían" (Monod, 2002: 122-123). En rigor, desde comienzos de la década de 1950 la industria cultural cinematográfica norteamericana había iniciado una clara segmentación de su audiencia, privilegiando al mundo juvenil a través de la producción de múltiples "teenpics" (Doherty, 2002): películas para las y los jóvenes y protagonizadas por éstos. En 1953, en The Wild One -del director Laszlo Benedek-, Johnny Strabler (Marlon Brando) encarna al líder de una pandilla motorizada que asola las calles de distintos pueblos del medioeste de los Estados Unidos de América intimidando a sus habitantes y "dispuesto a hacer tambalear los ideales de comodidad y bienestar del way of life norteamericano" (Solé, 2006: 166), filme que inaugura la expansión del estilo de los "black jackets" y sus variantes en el mundo (Teddy boys, Rockers, Blouson noir, Raggare, Halbstarken o Rebecos, según el caso) con la figura del joven duro, impenetrable, vacío e incomunicado con el mundo adulto que James Dean profundiza dos años más tarde en "Rebel Without a Cause". Películas, entre muchas, que se convertirán en un horizonte simbólico que articulará - un poco antes que la industria cultural 
musical segmentada-, la producción y reproducción de las primeras culturas juveniles en Norteamérica y Europa. Sólo dos años después, las huellas de estas primeras culturas juveniles aparecen en Chile.

El 13 de abril de 1959 y a sus probables 17 años ${ }^{3}$, Carlos Boassi Valdebenito, joven de clase media acomodada - "perteneciente a una familia adinerada y dueño de toda esa libertad en que se desarrollan las malas semillas" (Vea, 23 de abril de 1959, pp. 16-17)-; y vecino de la "señorial comuna de Ñuñoa" (Clarín, 22 de abril de 1959, pp. 1-2) en Santiago, usaba, como los personajes de James Dean o Marlon Brando, chaqueta de cuero negro, "su tradicional y característico tres cuarto montgomery" y vestía "un ajustado pantalón azul tipo 'pecos bill'” (Clarín, 21 de abril, p. 2). Hijo menor de 16 hermanos, de padre comerciante -inmigrante italiano- y madre chilena y dueña de casa, había llegado hasta $5^{\text {to }}$ de humanidades en el colegio confesional San Pedro Nolasco y poseía "vehículo propio, una elegante motocicleta italiana y (...) llave para entrar a su casa cuando lo desee" (Ercilla, 29 de abril de 1959, p. 16). Se peinaba a la gomina y tenía arrastre con las jovencitas "En todo sentido, desde físicamente hasta su forma de pensar... Era una persona alta, un metro ochenta (...) una persona de figura bastante bien agraciada (...) quebraba un poco la estructura (...)", rememora su hijo Carlos Boassi Leonición ${ }^{4}$ Coincide uno de sus amigos, Peter Mociulski:

Ambos teníamos una Ducatti, de 175 cc. Eran chicas, pero les sacábamos hasta 220 kilómetros por hora, porque en vez de sangre teníamos mezcla -bencina y aceite- en las venas. Éramos jóvenes, inmortales y sudábamos perfume Flaño y adrenalina (...) teníamos que espantar a las mujeres con un matamoscas. Estábamos hechos de miel ( $\mathrm{La}$ Cuarta, 19 de julio de 2006).

En octubre de 1958 Boassi Valdebenito había conocido en una fiesta juvenil a María Luz Tamargo González, estudiante de $1^{\text {er }}$ año de humani-

\footnotetext{
${ }^{3}$ El Registro Civil consignaba el nacimiento de Boassi el día 14 de febrero de 1943, por lo tanto, a la fecha del supuesto crimen, "Carloto" tenía 16 años y 2 meses. No obstante, la policía encontró el certificado bautismal extendido en la parroquia San Crescente estipulando que nació el día 22 de agosto de 1940. Esto lo convertía en mayor de edad -con 18 años y 7 meses- y por tanto en imputable desde el punto de vista de su responsabilidad penal. Un tercer documento en disputa fue la ficha dactiloscópica emanada del "gabinete de identificación" que asegura que Boassi nació el 27 de febrero de 1942. Finalmente el juez se atiene al certificado del Registro Civil, por tener mayor validez ante la ley y encarga un examen de discernimiento. (cf. La Segunda, miércoles 29 de abril de 1959, p. 16).

${ }^{4}$ Hijo mayor de Carlos Boassi Valdebenito. Su identidad -en contraste con el resto de informantes claves y los relatos de vida que aquí se citan- se revela por las características de la información entregada y con su consentimiento.
}

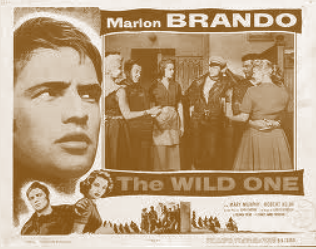


dades del Liceo de Niñas No 9 e hija menor de Alberto Tamargo, dueño de la céntrica librería santiaguina "Tamargo". "Comenzó a visitarla en su casa y pronto salieron juntos en motocicleta a las [boites] 'Brujas' y el 'Charles"' (Ercilla, miércoles 29 de abril de 1959, p. 17). La relación que tenía con su novia -de 15 años de edad- pasaba por un mal momento. "Carloto" como le apodaban sus amigos, había hecho un viaje aventurero al norte de Chile y a Bolivia -"mezcló la emoción de la velocidad con el vagabundeo" (Vea, 23 de abril, p. 17)-, lo que disgustó a su pareja. El sábado 10 de abril, María Luz se llevaría otro disgusto debido a que Carlos prefería "la moto a ella" (Ercilla, 6 de mayo de 1959, p. 8) y no la iría a ver el día domingo debido a que viajaría "a participar en una carrera de motos que había organizado la compañía de bomberos de Curacaví" (op. cit., p. 9). Ese sábado y durante los reproches, María Luz le dijo que sería capaz de cualquier cosa, "hasta de matarse" (op. cit., p. 9). Seguidamente, le pidió que le llevara un arma "para quitarse la vida", puesto que habían estado discutiendo "y yo estaba en una situación inferior a ella... Ella era muy dominante. Me dijo 'tráeme tú el revólver si eres tan hombrecito"' (Vea, 7 de mayo, p. 16). Para reconciliarse, la tarde del lunes 13 de abril pasó a buscarla en su moto Ducatti de 175 centímetros cúbicos para salir de paseo. Unas horas antes, Carloto le pide un revolver a su amigo Orlando Zunino. "Yo llegué a verla con la disculpa que le traía la pistola. Cuando se lo dije se rió. Yo también reí. Nos fuimos caminando por Vasco de Gama tomados de la mano y haciéndonos bromas" (Vea, op. cit., p. 16). Se pararon en la calle Cruz Almeida y luego de un rato, discutieron. De un bolsillo de su casaca de cuero, Carloto extrajo el revólver Famae 6.35 milímetros prestada por su amigo.

A las ocho de la tarde, una vecina escuchó un disparo. Al acercarse al lugar vio a la joven tirada en el suelo. Desde su sien derecha salía un hilo de sangre. María Luz fue trasladada por otras personas hasta el Hospital de Neurocirugía, donde murió diez horas después. Carlos Boassi Valdebenito se escondió durante dos semanas, lo que alimentó el pánico, la criminalización mediática y la sanción de la opinión pública. Finalmente se entregó ante el magistrado Raúl Guevara Reyes, quien ordenó su inmediata detención. Carloto enfrentaba cargos de homicidio. La actitud de Carloto era sospechosa. El que pasó a ser un símbolo de los llamados "Coléricos" en ese entonces, no le prestó ayuda a su novia de 15 años que se desangraba y huyó. Durante meses la investigación arrojó resultados contradictorios, nutrida de peritajes contrapuestos y testigos y testimonios descalificados ${ }^{5}$.

\footnotetext{
${ }^{5}$ Finalmente y después de meses de escrutinio periodístico y diligencias policiales, la justicia concluye su labor. El proceso consignado con el número 48.598 del Sexto Juzgado del Crimen de-
} 
La singularidad del incidente protagonizado por Carloto y la opacidad del móvil concitaron la atención pública. La prensa escrita informó y provocó un "pánico moral" (Cohen, 2002) sin precedentes en Chile en relación a estas nuevas identidades juveniles. Sentencias como "Pandilla temible la de Boassi. (...) se habla de la existencia de un comando secreto de motocicletistas que se agrupaban en un club deportivo llamado "Taurus"' (La Tercera, 17 de abril de 1959); o pies de fotografías donde se cifra: "La inocencia y belleza de la liceana estuvieron a punto de reducir al rebelde pandillero. Pero de pronto reaccionó el 'Carlotto', con pasiones morbosas y balazos" (Vea, 23 de abril de 1959, p. 16), son recurrentes. El abogado de la familia de la joven María Luz, Alberto Cumplido, sintetizará la hipótesis implícita sobre el móvil del supuesto homicidio que baraja desde el inicio una parte importante del periodismo escrito: “(...) se dejó llevar por una pasión cinematográfica. Esto podría compararse con la película Rebelde sin causa, en que los muchachos, por razones que ignoraban, se lanzaban al abismo en autos de carrera. Se trata de la mentalidad actual de nuestra juventud" (Clarín, 22 de abril de 1959, p. 3). El resto de la prensa -aunque con matices- reaccionará del mismo modo, con información tendenciosa y escasamente contrastada.

Más allá, el sensacionalismo mediático abre la primera vía de reflexión y debate público sobre estos nuevos actores. Además de quedar consignados en el proceso los distintos informes periciales, se compendian allí testimonios de jóvenes del entorno de Carlos y María Luz. Asimismo, las investigaciones periodísticas -reportajes en profundidad- no sólo desentrañan las especificidades judiciales del caso, sino que exploran, a partir de algunas fuentes calificadas, las aristas biológicas, sociales, educativas y sicológicas que explican el crimen y la aparición de estos colectivos juveniles en la sociedad chilena. En efecto, el día 29 de abril de 1959, la revista Ercilla hace un extenso reportaje al "drama juvenil" (sic), titulado "Una generación en la encrucijada”. El reportaje inserta una extensa opinión del renombrado siquiatra -y ex ministro de salubridad- Juan Garafulic donde, entre otras ideas, plantea:

talla en sus 322 carillas los pormenores del confuso incidente. Ante el magistrado el joven Boassi alegó su completa inocencia. Aseguró que María Luz le arrebató de improviso el arma cuando se la mostró y que ella misma se descerrajó el tiro en la cabeza. "Fue una chacota que resultó fatal", diría a la prensa Boassi Valdebenito en esos días (Ercilla, 6 de mayo de 1959, p. 8). Tras cumplir la mitad de su pena y luego que la justicia acogió una petición de clemencia solicitada por su familia y rubricada por el Presidente Eduardo Frei Montalva en diciembre de 1967, Carloto salió libre. "No juzgaron al 'Carloto', sino que a los 'coléricos', a la juventud rebelde”, le dijo Boassi al periodista José Carrasco, cuando finalmente obtuvo su libertad ( La Cuarta, 30 de agosto de 2003).

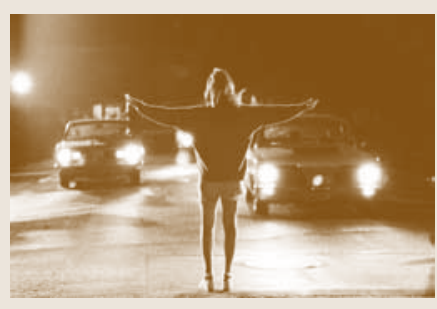

Escena de Rebelde sin causa 
Es fundamental que el hombre recupere su autoridad y su papel de jefe de hogar. La mujer estará pidiendo a gritos retornar al hogar dentro de 40 ó 50 años. El varón se acostumbró a descansar en la esposa y los hijos que aportan dinero al hogar. De este modo el hombre no tiene ninguna autoridad doméstica (...). Solamente el dinero y los bienes materiales tienen importancia. Las chicas exigen vestido de fiesta y estreno en sociedad; el chico motoneta y mesada. (...) En el terreno juvenil el resultado es que la mujer se ha puesto "cara". Antes bastaba un paseo a pie por el forestal y una docena de barquillos para galantear a la novia. Ahora se necesita automóvil, whisky y boite para llegar al mismo resultado. El muchacho requiere cada vez de más dinero para llenar la función biológica del amor (Ercilla, 29 de abril de 1959, p. 16).

Una semana más tarde, en las páginas centrales de la misma revista ( $E r$ cilla del 6 de mayo de 1959), aparece una selección de opiniones de educadores -entre ellos el sacerdote Heriberto Lagos, director del colegio donde estudió Boassi-. Entre las respuestas a la pregunta si los "coléricos o rocanrrolistas" (sic) son un grupo exclusivo de la época, y las causas del aumento de la "delincuencia infantil", el directivo responde que estos grupos existían antes pero "más moderados" y que su aparición se debe "a la crisis moral y económica de los hogares. La falta de formación sólida y cristiana. El ambiente materialista actual, el cine, la prensa". Más adelante agrega: "otro factor que hay que considerar es el dinero dado en mesadas abundantes que no corresponden a un esfuerzo real" (Ercilla, 6 de mayo de 1959, p. 9). En tanto, la prensa de ciudades de provincia como Valdivia, venía dando cuenta regularmente sobre el juicio de Boassi, hasta hacerse parte opinante en una editorial publicada en el periódico El Correo de Valdivia. Bajo el título de “¿Jóvenes Coléricos?" el editorialista asocia el confuso incidente protagonizado por Carloto como parte del "desquiciamiento moral de la juventud y la adolescencia" debido a "los ritmos raros y agotadores como el rock'an roll, los trajes chillones, las camisas sueltas, y los pantalones ajustados a la pierna, los gritos y las carreras a grandes velocidades en débiles motonetas" (El Correo de Valdivia, 29 de abril de 1959, p. 3).

Las opiniones expresan un doble alegato -común en la literatura científica y edificante de la época- dirigido a los cambios modernizadores que impactan tempranamente a los sectores privilegiados de la sociedad chilena y que comienzan a mutar el rol de la familia y particularmente de la madre en la crianza de los hijos debido a su nuevo rol -ya no como mera reproductora, sino como productora-, y la del padre como "autoridad" en la vigilancia y control de las y los jóvenes. Al mismo tiempo, su reclamo va dirigido a la emancipación material que supone la "mesada" o gratifica- 
ción regular en dinero otorgado por los padres a la o al joven, que amplía su moratoria de la esfera educativa a la de la holganza. Así, habilitándolo como consumidor(a), posibilita su participación en el emergente mercado del ocio juvenil (cine, boites, "carreras a grandes velocidades", etc.) y su correlato: la formación de "patotas" o "pandillas" que instalan sus prácticas "desviadas" en los intersticios de la vida institucional. De esta manera, el acceso a la industria cultural segmentada que posibilita el ocio juvenil se considera una amenaza por cuanto se sitúa en un espacio de frontera entre la familia, el trabajo o la escuela donde el control de tutores o supervisores es limitado o inexistente (cf. Boëthius, 1995).

En la conservadora sociedad chilena del momento, las interpretaciones desviacionistas del fenómeno se naturalizan y son mecánicamente reproducidas en los medios a partir de la criminalización, estigmatización y la homologación de la condición juvenil a la entelequia de "problema", "tormento" o "drama": un colectivo amenazador a la vez que vulnerable. Lecturas que se anclan en los primeros aportes científico-sociales sobre el comportamiento juvenil y la conformación de bandas -o "gangs"- a principios del siglo XX en los Estados Unidos (v. gr. Stanley Hall en 1904 y las investigaciones de miembros de la Escuela de Chicago, como Robert E. Park en 1915), pero de sobremanera, con las investigaciones que surgen desde principios de la década de 1940 por parte de la sociología estructural-funcionalista norteamericana. En este sentido, es importante subrayar que las investigaciones científico-sociales sobre juventud en Chile y América Latina a mitad de la década de los '50 tenían un precario desarrollo, cuyo acervo conceptual-situado genéricamente en el ensayo- era provisto básicamente por la teoría generacional de Ortega y Gasset y los aportes de Juan Carlos Mariátegui como su contrapartida crítica (González, 2004b). Aunque a fines de 1930 aparece la figura de Aníbal Ponce con dos obras científicas referidas a estos colectivos -Psicología de la adolescencia (1938) y Ambición y angustia de los adolescentes (1939)-, sus aportes convergen y glosan la mayoría de las investigaciones desarrolladas en los Estados Unidos y Europa desde principios de siglo en ese campo disciplinario (particularmente las de Stanley Hall, Jean Piaget y Eduard Spranger). De este modo, las miradas teóricas y enfoques que educadores/as y sicólogos/as de la región hacen suyos no van más allá de las posibilidades que las ciencias sociales precariamente institucionalizadas -como la psicología y la sociología-, tuvieron para hacer de la realidad juvenil un fenómeno "descifrable". Miradas y enfoques que se prenden particularmente de un estructural-funcionalismo estigmatizador, preocupado por normalizar a los "jóvenes disfuncionales o desviados" ge- 
nerados por los procesos de industrialización y migración rural-urbana. Enfoques y referentes teóricos derivados, entre otros, de Talcott Parsons, el cual conceptualiza la juventud como un segmento social que, desajustado por una transición abrupta provocada por el paso de la sociedad tradicional a la moderna, necesita y reclama -en su "rebeldía"- espacios de integración: "una disposición a trabajar al interior del sistema más que contra él" (Parsons, 1963: 130). Estas condiciones, según los supuestos del estructural funcionalismo, generan una conciencia generacional inédita en los grupos de edad -sin distinción de clase-, que cristalizan una verdadera "cultura" autónoma de normas y valores centrados en el consumo hedonista, cuyo resultado sería la irresponsabilidad, confrontación con el mundo adulto, atractivo físico como fuente de estatus, entre otras (cf. Parsons, 1963). Desde la psicología, en tanto, los referentes conceptuales utilizados provienen de la comprensión de la juventud como un estado universal del ser humano donde se libra una batalla interior turbulenta entre el instinto y la cultura, signado por una carencia de racionalidad y exceso de pasión -características que explican las desviaciones de las normas-; y una fase de confusión en la búsqueda de la propia identidad (cf. Erikson, 1950). En este contexto adquiere toda su coherencia y potencia expresiva el mote de "coléricos"6 con que la opinión pública y los medios califican a estos nuevos actores "rebeldes", agresivos y airados.

Más allá, el papel generativo y la responsabilidad de las instituciones y mass media en la construcción de estos grupos como sujetos desviados, como "diablos populares", parece obvio, en la medida que los estereotipan y etiquetan contribuyendo a que el predicamento del estigma se corporeice en modelos que informan a la sociedad cuáles son las conductas y roles a evitar (Cohen, 2002). Con todo, la profusión informativa y el pánico moral generado a partir del episodio, no sólo ilumina los referentes teóricos y conceptuales con los que contaba la sociedad chilena para entender el surgimiento de estas nuevas identidades juveniles, sino también conduce a insinuar de manera parcial indicios sobre la extensión y profundidad de estas manifestaciones identitarias en el país.

\footnotetext{
${ }^{6}$ Si bien el término sufrirá mutaciones semánticas desde la mitad de la década de los '60 (con la "invasión" del rock británico), el apelativo -en clara referencia a la teoría greco-latina de los cuatro humores-, se fragua en la segunda mitad de la década del '50. A mediados de la década de 1960, el término aparece definido en el diccionario de chilenismos de Morales Pettorino (2006: 652) como “joven rebelde y desinhibido de la década de los '60 que se caracterizó por su constante actitud de protesta manifestada -entre otras cosas- por un lenguaje, aspecto físico, y vestimentas extravagantes que resultaban innovadores y o llamativos por lo novedoso o fuera de lo común”.
} 


\section{ESTIGMAS Y EMBLEMAS: MOTOS, ESTILO, CLASE Y MASCULINIDAD}

Los resultados preliminares de nuestra investigación -sustentada en análisis documental e historias de vida- sobre más de treinta sujetos que experimentaron su condición juvenil (biológica y/o sociocultural) entre los años 1955 a 1967, y que participaron o conocieron algunas de estas expresiones culturales en dos enclaves urbanos ${ }^{7}$, permiten avizorar parte de la profundidad y extensión del fenómeno, complejizado -en la memoria y la biografía- a partir de las posiciones de clase, género y territorio. Aunque la muerte de Boassi Valdebenito nos impide acercarnos desde el "sí mismo" a su trayectoria biográfica y al arquetipo juvenil que encarna, el relato de múltiples informantes de su generación y la de su propio hijo -Carlos Boassi Leonicio- nos permiten acceder a algunas claves de estos colectivos a través de sus filiaciones, prácticas e imágenes culturales.

Boassi Leonicio tuvo una estrecha relación con su padre. Su profesión y alta dedicación profesional -odontólogo- no le impidió trabajar junto a él en los diversos negocios que emprendió después de su excarcelación. Las cadenas de experiencias transmitidas por su padre en torno al episodio le permitieron a Boassi Leonicio entender de primera fuente la trayectoria y condición juvenil de Carloto a fines de la década de los '50. Dicha trayectoria se comprende por algunas condiciones que terminarán construyendo la doble extranjería de Boassi Valdebenito: el ser hijo menor de un inmigrante italiano "con una pequeña fortuna" (comerciante de porcelana europea, dueño de dos hoteles y constructor inmobiliario); y expresar pública y "dramatúrgicamente" las diferencias con el mundo adulto -"espectacularizar" su identidad juvenil- a través del estilo y prácticas de sociabilidad intrageneracional codificadas como extrañas y transgresoras.

En efecto, después de abandonar la educación formal, Carloto no recibe "mesada" de su familia, pero consigue empleos parciales en el entorno barrial relacionados directamente con su nueva afición: las primeras y onerosas motocicletas que arriban al país vía importación directa:

(...) Mi papá en ese tiempo ayudaba a un mecánico (...) algunas horas en la semana, iba dos días a la semana y el fin de semana también

${ }^{7}$ La capital de país -Santiago- y una ciudad intermedia regional situada en el sur de Chile -Valdivia-. El enfoque metodológico -fundamentalmente cualitativo- buscó, más que la representatividad "estadística" territorial y grupal, la posibilidad comprensiva que ofrecía: su representatividad analítica.

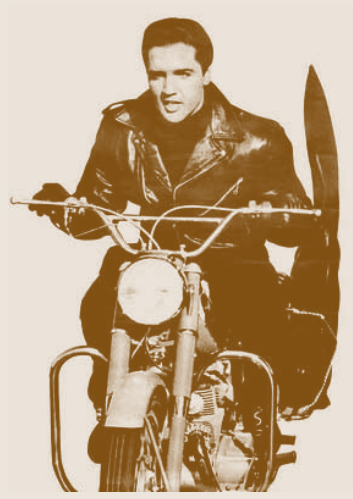

E. Presley 
y aprendía de eso. Mi papá, siendo de una familia de clase social media, o media alta, nunca contó con que el papá le pasara plata, o sea muchas veces él ganaba plata trabajando en estos talleres y ahorraba armando, arreglando o pintando motonetas para poder hacer el gran viaje que era en verano (Carlos Boassi Leonicio).

Si bien Carloto, como otros muchachos, trabajaba para obtener el poder adquisitivo que le permite acceder a estos bienes materiales y simbólicos juvenilizados, gran parte de su vida material estaba asegurada, debido a que vivía al alero de sus padres y el dinero obtenido iba directamente para usufructo propio y no para colaborar en la economía doméstica (como sucedía con una porción importante de las y los jóvenes chilenos de la época). De este modo y con su empleo, Carloto aprende mecánica y logra ahorrar dinero suficiente para comprar motocicletas de segunda mano, "modificarlas" y realizar lo que será uno de sus pasatiempos favoritos, como competir en carreras de motocicletas fuera de la capital.

Así, su semiautonomía económica le permite usar y apropiarse tempranamente de un medio de transporte originalmente "adulto" y respetable -industrializado y extendido desde la Segunda Guerra Mundial-, pero su manipulación y modificación ahonda los signos de su juvenilización en la medida que, como plantea Hebdige (2004: 144-145), esta operación de bricolage subvierte el significado original del ciclomotor para transformarlo "en un amenazante símbolo de solidaridad de grupo", eminentemente masculino:

Más bien eran hombres. Porque acuérdate que en esa época el pantalón no era tan popular como ahora. (...) Entonces los motoneteros era más de los hombres (...). (Alicia Acevedo, Nuñoa, Santiago ${ }^{8}$ ).

[a la mujeres] les gustaba andar atrás, pero motoristas no, no quiero tildarlo de machismo, pero eran los hombres los que andaban en motos. (Jorge Sanhueza, Santiago Centro).

Una parte importante de sus actividades focales era realizar viajes en motocicletas que se extendían durante el verano y emprender excursiones

\footnotetext{
${ }^{8}$ Este, como los otros informantes referidos en este trabajo, aparecen con seudónimos para resguardar su anonimato. Sin embargo, se procedió a salvaguardar la equivalencia cultural de sus nombres y apellidos en cuanto implicaban un origen sociocultural específico. En relación a su procedencia socio-territorial, se optó por identificar la comuna y ciudad donde el informante experimentó su condición juvenil utilizando las actuales divisiones político-administrativas buscando la equivalencia socio-espacial en relación a la época donde los informantes sitúan sus testimonios.
} 
a las playas del litoral central donde algunos muchachos tenían segundas residencias. En estas actividades se carnavaliza la emancipación del control parental y las normas de sociabilidad a través del estilo y una actitud desenfadada y gamberra. Sus jopos engominados, cierto machismo arrogante, chaquetas de cuero y el ruido ensordecedor de sus motocicletas resultan un desafío a la sintaxis de la vida cotidiana de sus pares $-y$ de los pequeños balnearios donde llegaban-, que termina reforzando su jerarquía social, económica y cultural de pertenencia:

¿El Carloto? (...) sabía que vivían ahí, en esa casa [balneario de San Sebastián], llegaban con sus motos, metiendo bulla, pasaban por todos lados a cualquier hora. (...). Los coléricos eran gente de recursos. (...) [eran] violentos en su actitud, prepotentes, con las motos, vestían de negro, todo de cuero y demostraban que tenían plata. Yo creo que nosotros los rechazábamos (...), como grupo de clase media alta, eran prepotentes, es decir [decían] aquí vamos nosotros déjennos pasar, y a uno de ellos, no me acuerdo cómo se llama, parece que lo acusan de que mató a la novia (Celia Calvo, La Cisterna, Santiago).

Aunque colérico significaba para algunos "que te gustaba ser libre (...) que nadie te dijera algo (...) un cabro sin responsabilidades (...) porque todos los papás de ese tiempo eran muy autoritarios" (Jorge Sanhueza), poco a poco la imagen de los coléricos espejea con los "teenpics" norteamericanos y se va constituyendo y asentando en torno a la alteridad, la autoridad y la masculinidad, por cuanto "ellos eran los líderes, los choros, las cabras se volvían locas” (Boassi Leonicio).

Ocurrido el hecho de sangre protagonizado por Carloto, la imagen se densifica y las primeras señales de tribalización juvenil quedan sometidas a un repertorio crítico de las instituciones -policiales, judiciales y mediáticas- que pugnan por hegemonizar el significado de las mismas a través del labelling. Consecuentemente, en la experiencia de gran parte de los actores entrevistados estos significados se cristalizan y retroalimentan, y las imágenes de los “jóvenes otros” y "masculinos, elíticos y minoritarios" que emergen son especulares a este repertorio.

De esta forma, por un lado se reiteran y reproducen en la memoria las distinciones establecidas por los mass media que escinden la experiencia de la identidad juvenil a través de la oposición a los valores y actitudes representados por los jóvenes más radicales ligados a la imagen de Dean, Brando o Presley sintetizada y criollizada en los coléricos y Carlotos; y por otro, aparecen las distintas formas de apropiación $-\mathrm{y}$ vivencia- del estereotipo 
identitario retroalimentada por los medios de comunicación de masas y la industria cultural segmentada.

En el primer caso, una parte sustantiva de las narrativas biográficas insisten en la distancia con el arquetipo identitario, destacando su existencia minoritaria y masculina, concentrada en los sectores más acomodados, cuyo comportamiento asistémico es rememorada como un tipo de violencia juvenil cuya fuente es la clase social y el género de pertenencia:

$\mathrm{Al}$ choro, se le decía Carloto. Cuando era un gallo medio pasado, macanudo como ahora, le decían Carloto (...). Pero esos eran una minoría. No eran bien vistos tampoco. Esos carlotos eran un ícono, porque era un gallo de allá de Las Condes [barrio alto] (...) La gente era muy clasista: los ricos eran los que tenían las motos. Eran gallos malos. (...) Pero uno instintivamente se apartaba (Leonardo Pérez, San Bernardo).

En esta dirección, es necesario precisar que la imagen construida de estos colectivos en torno a las clases dominantes vertebran el imaginario testimonial, cuyo correlato estructural tiene un asidero parcial, pero efectivo. Inversamente a lo sucedido en los Estados Unidos y Europa, en Chile el prototipo identitario juvenil colérico/carloto no surge, ni se reproduce en las capas obreras, populares o subalternas, como sí ocurre con los Motorbike boys, Teddy boys, Rockers o Blouson noir.

En Chile, el acceso a los bienes culturales juvenilizados lo tienen, en un primer momento, los hijos de las capas más acomodadas de la sociedad. Tal como lo demuestra Ahumada (1958) desde principios de la década de 1950, el país estaba inmerso en el modelo económico de sustitución de importaciones, presentaba un lento desarrollo industrial y un retraso abismal en el agro debido a la concentración de la tierra -la reforma agraria comenzará de manera eficaz sólo en la segunda mitad de la década del '60-. Todo ello configuraba una sociedad con desigualdades estructurales e inequidades sociales evidentes: "al finalizar la década de 1950 el 9\% de la población activa percibía alrededor del $43 \%$ del ingreso nacional" (Correa et al., 2001: 186). Por lo mismo, la capacidad de adquisición y consumo de productos importados -emblemas de la nueva condición juvenil como los jeans, las motocicletas, chaquetas de cuero, revistas juveniles, discos y tocadiscos, entre otros- estaban notablemente restringidos para los estratos populares, cuyos jóvenes no sólo no reciben una "mesada" ni están en condiciones de metabolizar estos bienes simbólicos segmentados, sino que en su condición 
de trabajadores -y en menor medida de estudiantes ${ }^{9}$, no experimentan el privilegio de la semi-independencia familiar $-\mathrm{y}$ la propia condición juvenil- puesto que resultan un complemento económico axial para la economía doméstica:

Uno creció en una época que todo era difícil, que todo costaba (...) había gente que compraba dos cucharadas de té para tomar a la hora de once, y era una familia de cuatro a cinco personas (...) empezaban todos muy jóvenes a trabajar, mi esposo (...) a los ocho, nueve años ya entró a trabajar a una fábrica lijando juguetes. Los jóvenes eran adultos por la misma situación y debido a eso que todos los matrimonios se hacían muy jóvenes (...) (Sandra Rivera, San Miguel).

Por otra parte y en el segundo caso, aparecen los efectos más evidentes del labelling y la recepción directa de los mass media, jóvenes que transformarán el estigma en emblema. Pese a las agudas desigualdades estructurales que presenta Chile en buena parte de la década de 1950, acercándonos a la década de 1960 los sectores mesocráticos -situados fundamentalmente en las urbes- se irán ensanchando lentamente con la expansión educativa, el crecimiento de la burocracia estatal, los efectos de la concentración urbana y la migración campo-ciudad. Ello explica que la aparición de las primeras culturas juveniles no sólo se registre en las capas altas de la sociedad chilena, sino también en las nuevas clases medias metropolitanas. Es esta diseminación las que nos permite profundizar en estos colectivos y dar cuenta de su extensión.

La historia de vida de Jorge Sanhueza Álvares -nacido 1937- es ejemplar en este sentido. Hijo de un suboficial del Ejército y una madre dueña de casa, Jorge tuvo una infancia signada por la austeridad, la disciplina y el control parental, de los que se emancipa radicalmente. El trabajo estable e institucional del padre posibilitó a la familia de Sanhueza experimentar la movilidad social suficiente para engrosar las capas medias del país. Llegó a Santiago a los 17 años, después de vivir y estudiar en diversas ciudades de Chile. Ingresó a la Escuela de Especialidades de la Fuerza Aérea en 1958 donde estuvo tres años estudiando y trabajando en mecánica de aviones. En un breve lapso y de manera precaria, Sanhueza se independiza económicamente y junto a compañeros de trabajo y amigos del barrio comienzan

\footnotetext{
${ }^{9}$ Para 1960, sólo un 9,87 \% de la población juvenil de 15-19 años era estudiante de Enseñanza Media (I.N.E. 1999).
} 
esforzadamente "a comprar motos (...) a juntarnos en grupo, siete, ocho, diez, quince solteros y salir", intentando recuperar las horas de trabajo en las que no se habían pertenecido a sí mismos. En las tardes y fines de semana se reúnen asiduamente en plazas y calles del centro de Santiago, emprenden excursiones en sus motocicletas a diversas playas próximas a la capital y asisten a boites y fiestas. A un año del episodio protagonizado por Carlos Boassi y pese a las distancias de clase y territorio, la nombradía para describir al arquetipo identitario -“colerismo" más acusado- se extiende y reapropia. Así, Sanhueza y sus amigos comienzan a identificarse con el apelativo de "Carlotos":

Y nosotros agarramos también, entonces nos llamaban los Carlotos a toda la chusma que seguíamos abajo (...). Lo que significaba ser Carloto era ser rebelde, rebelde a lo establecido, a la sociedad (...). Y ¿Por qué Carlotos? Porque el joven éste del que se usó el nombre, mató a una niña, a su polola [novia], en rebeldía, porque a lo mejor la polola andaba con otro niño, se sintió celoso, no supo arreglar sus diferencias, y se le pasó la mano, le pegó un balazo. (...). La familia del Carloto tenía plata, no era amigo nuestro era de por allá arriba, era de Las Condes, no lo conocí nunca (...). Todo el grupo de esos años y sobre todo si andaban en motos se llamaban Carlotos (...) (Jorge Sanhueza, Santiago Centro).

Parte de la narrativa biográfica de Jorge Sanhueza evidencia las consecuencias del labelling vehiculizado por los mass media. Este no sólo modifica las representaciones de la realidad, sino que altera, igualmente, la realidad misma, al orientar el comportamiento de los sujetos, los que comienzan a actuar y configurar su propia identidad de acuerdo a estas nuevas representaciones. Tal como plantea Thornton (1995), los medios de comunicación masivos y la industria musical serán, finalmente, un agente activo en la creación y reproducción de las culturas juveniles a través del etiquetamiento, en la medida que visibilizan las prácticas y estilos juveniles restringidos y ghettizados a través de un proceso de confiscación, legitimándolas e inoculándolas masivamente en el "adolescente global" y en la propia escucha social. Del mismo modo, tal como lo ha demostrado Cross (1998) para el caso de los Teddy boys -la primera cultura juvenil surgida en Inglaterra hacia 1954-, una parte importante del sustrato identitario de estos colectivos está formado por lo que las representaciones de la sociedad adulta -a través de los mass media y otras instituciones- tienen y esperan de estos jóvenes. Así, se constituyen en una profecía autocumplida.

Lo anterior es relevante por cuanto la teoría producida sobre este tipo 
de colectivos en Europa y los Estados Unidos desde finales de los años 60 revisitaron el papel tiránico y unidireccional de los medios y el mercado segmentado en la producción y reproducción "automática" de culturas juveniles. Sin embargo, los coléricos atraviesan en Chile dos microprocesos, caracterizados, en un primer momento y desde 1955, por una asimilación pasiva de la industria cultural segmentada de tipo cinematográfica $y$, en un segundo momento -a partir de 1959 en el que se refuerza su identidad y etiquetaje con el apelativo radical de Carlotos-, de apropiación activa y expresiva. De esta forma, a partir de ese año el efecto de este etiquetaje operacionalizado por los medios tiene consecuencias bidireccionales en estas culturas juveniles, en la medida que son estructurantes, pero igualmente estructurados por las propias prácticas culturales y materiales. Así, se produce un proceso de confiscación simultánea (de jóvenes y medios) conducido y sintetizado, fundamentalmente, por el estilo. Las primeras señales de este proceso quedan de manifiesto en la trayectoria biográfica de Jorge Sanhueza:

A mí me influyó mucho Elvis Presley, no en el canto porque no era bueno para cantar, pero sí en la vestimenta, en la manera de vestirme. También el otro, el rebelde sin causa, el James Dean (...). Varios de nosotros, empezamos a usar pantalones rosados en ese tiempo, a usar camisas celestes o camisas rosadas de manga corta, un hombre no usaba eso en ese tiempo pero Presley usaba de ese tipo... el color caqui lo usaba mucho, café claro, y pantalones rectos... entonces todos tratábamos de imitarlo (...). (...) la gracia era andar en moto, porque motos no habían como ahora (Jorge Sanhueza, Santiago Centro).

En tanto, el hijo de Boassi narra los primeros efectos de apropiación activa del estilo a propósito del abrigo popularizado inicialmente por el general inglés Bernard Montgomery, cuya mediatización y juvenilización se le atribuye al actor de teenpics norteamericano Montgomery Clift:

Se vestían con chaquetas de cuero y montgomery. (...) Dicen que el montgomery lo inventó mi papá, yo no sé de adonde lo habrá inventado, pero por lo menos harta gente a mí me a dicho 'él inventó el montgomery". (...) los botones eran como de hueso al principio, entonces dicen que mi papá se compró un chaquetón y él le puso otros botones y (...) y por eso le pusieron 'el abrigo Carloto' (...) (Boassi Leonicio).

Al poco tiempo las actividades focales procesan el repertorio estilístico cuya cantera nutricia son las intervenciones e inflexiones que le dan a 
la vestimenta y a la apariencia. Como plantean Clarke (1976: 175-191) y Hebdige (2004: 139-174) el estilo aparece como una configuración activa, selectiva y coherente donde se urden bienes simbólicos y comportamientos sometidos a una resemantización dinámica que logra organizar un sentido de pertenencia y distinción grupal, básicamente a través del bricolage -la forma en que objetos, mercancías y símbolos son reordenados y resituados para producir nuevos significados- y la homología -la correspondencia simbólica entre objetos, valores, estilos de vida, experiencias subjetivas, entre otros, que se emplean para expresar y reforzar la identidad grupal-. En nuestro caso, así aparece, por ejemplo, la mixtura "coherente" del atuendo, donde se entrelazan motocicletas, chaquetas de cuero, montgomerys y 'motonetas' (casaquillas sin mangas utilizadas para bailar y deambular).

Es importante considerar que esta declaración pública de identidad juvenil por vía del atuendo es prácticamente inédita en el país debido a que muy entrada la década de 1950 el espectro del vestuario para la población joven masculina y femenina era muy limitado y estaba modulado -en un contexto de "simulacro de integración internacional"- por pequeñas fábricas y costureras de barrio (Montalva, 2004): ropa de trabajo durante la semana y tenida de domingo los fines de semana. Coléricos y Carlotos -como sus homólogos en el mundo- cruzan la división entre una sastrería funcional y un uso performativo.

\section{POLOLEO, MALONES Y MATINÉ}

Aunque "todo iba en torno a las motos (...)", la mecánica, las carreras -"se llegaba al fin de semana con la motoneta recién arreglada (...)" (Boassi Leonicio), estas primeras culturas juveniles cuentan con tiempo disponible suficiente para juntarse con muchachas y muchachos del barrio en las tardes y fines de semana. Las pequeñas y medianas plazas vecinales se constituyen en espacios cotidianos de sociabilidad e interacción que amplía sus prácticas sociales. Allí planifican los "malones" (reuniones domésticas y cooperativas bailables), excursiones a la playa y a las boites (lugares públicos de esparcimiento y baile progresivamente juvenilizados) y, de sobremanera, las salidas a la matiné (exhibición de filmes que tienen lugar en las primeras horas de la tarde). Espacios y tiempos que posibilitan a muchachas y muchachos escenificar su identidad juvenil no sólo a través de la vestimenta, sino también por medio de los nuevos ritmos que arriban lenta, pero decididamente al país desde mediados de 1950, como el rock and roll.

En esta dirección, cabe señalar que una parte importante de la "de- 
mocratización" de la condición juvenil en este período se debió -en los sectores mesocráticos y en menor medida en los populares- al acceso a las producciones cinematográficas en los cines comunales y de provincias, que transportan la estética visual-juvenil y también la música incidental de sus procesos de juvenilización, como el rock and roll. Si bien durante gran parte de la década de 1950 el acceso a los bienes simbólicos juveniles (discos, tocadiscos, vestuario, etc.) estaba limitado a los sectores más acomodados y la programación radial seguía siendo dominada por el gusto adulto (tangos, mambos, boleros, rancheras y corridos mexicanos y canciones de raíz folklórica ${ }^{10}$ ), desde el estreno de Blackboard Jungle en 1955, las matinés multiplican su funcionalidad juvenilizante e interclasista: a la par que espacios semiocultos para el escarceo amoroso, son el vehículo que esparce la melopea y los compases cuyo consumo está restringido por las condiciones económicas o territoriales y casi vedados en los medios de difusión radial, particularmente en provincias. Durante la segunda mitad de la década de 1950 la exhibición de teenpics en Chile, especialmente en Santiago, será abundante, particularmente los dedicados al rock and roll, los que ascienden a 8 filmes sólo entre los años 1956 y $1957^{11}$. Todo ello sin contar a Blackboard Jungle y Rebel Without a Cause que llegan a la mayoría de provincias de Chile y que se mantienen en cartelera durante más de tres años.

De esta manera, la matiné suplirá la ausencia de una industria musical segmentada a nivel local que difunda el nuevo ritmo, la que aparecerá e impactará de manera decisiva en las nuevas ramificaciones del arquetipo juvenil Colérico ("Rocanroleros/as") recién desde principios de 1960 (Salas, 2003; Ponce, 2008 $)^{12}$. Varios testimonios evidencian el impacto de la matiné en relación a la propagación del rock and roll:

\footnotetext{
${ }^{10}$ No obstante, debemos consignar que, aunque de manera muy incipiente, comienzan a surgir a fines de la década de 1950 los primeros programas radiales segmentados dirigidos a una audiencia juvenil. Destaca aquí la transmisión "en directo" -con asistencia de público en las radioemisoras- de la primera banda de rock and roll chilena "William Reb y sus Rock Kings" que se presentaron en noviembre de 1957 en Radio Minería (Ver revista Ecran, 19 de noviembre de 1957, p. 21).

${ }^{11}$ En efecto, entre estos años, según nuestro análisis del magazine de espectáculos Ecran, se estrenan, entre otras, las películas: Historia del rock and roll al compás del reloj (de Fred Sears) en diciembre de 1956; Rock, rock, rock, en enero de 1957; Al ritmo del rock (Dont' knock the Rock, de Fred Sears) en marzo de 1957; Baila, linda baila (Rock, Prety Baby, de Richard Bartlett) en julio de 1957; Crimen en la calle (Crime in the street, de Donald Slegel) en agosto de 1957; El joven extraño (The Young Stranger, de John Frankenheimer) en diciembre de 1957.

${ }^{12}$ Dichos colectivos se configuran en torno al desplazamiento y conjunción del arquetipo juvenil Colérico modelado por el cine hacia otro modelado esencialmente por el rock and roll criollizado.
} 
Íbamos a la matiné el día domingo; (...) cine Odeón se llamaba, en la octava avenida; íbamos todas las muchachas y los muchachos a ese cine (...) y uno se veía seguido con las amigas y allá mirando a los chiquillos y cosas así. (...) Para ir al cine había que portarse bien; (...) el día sábado en la noche dejaba el aseo hecho, el día domingo me levantaba iba a la misa, a Carmen Mena, (...) volvíamos, y ya después atenta hacer todo lo que había que hacer para que hubiera permiso y plata para la matiné (...) que era como a las dos de la tarde. (..) es que era un espacio para jóvenes (Sandra Rivera, San Miguel).

Adicionalmente, las matinés y el rock and roll imbricarán otros espacios y permitirán la juvenilización de otros actores: por un lado las muchachas, que sometidas a la vigilancia sexual y moral tienen hasta ese momento espacios mucho más restringidos de escenificación identitaria y, por otro, jóvenes de provincia y, en menor medida, de origen subalterno. Todos ellos encuentran en los malones y las boites lugares propios y axiales de expresión juvenil y relación intergenérica.

El caso de los malones es el de mayor extensión y los testimonios sobre la organización y experimentación son abundantes:

(...) ahí hacíamos malones, nos conseguíamos una casa para hacer una fiestecita y ahí cada uno llevaba algo, al principio a los 16 años eran puros refrescos, no había copete, pero dos o tres años después ahí eran con todo. Y ahí bailaban rock and roll (...). Así que ahí me quedaba conversando, mirando, tratando de acercarme a alguna chica que a uno le gustaba (Lorenzo Carmona, Valdivia).

Los malones en que cada uno llevaba algo, en eso se ponían de acuerdo qué cosa llevaba cada uno (...) entonces se conversaba y se bailaba y se tomaba poco (Alicia Acevedo, Ñuñoa).

Dichos convites tienen la particularidad de segregar explícitamente a los actores adultos al interior de la familia y la comunidad, convirtiéndose en pequeñas brechas toleradas para las manifestaciones de moda, estilo y sociabilidad juvenil, que incluye pequeñas transgresiones como el consumo limitado de alcohol y la gimnasia "carnal" que implica la rapidez y destreza del rock and roll. Es en el malón, por ejemplo, que las muchachas pueden explicitar por medio de la sofisticación del atuendo y del peinado su condición juvenil y experimentar, como los varones, el placer de ser miradas. Los colores llamativos, las faldas tipo "plato" -hechas generalmente por familiares y costureras a imitación de la moda norteamericana- permiten a las 
muchachas obtener cierto control sobre su cuerpo y acceder a una filiación identitaria vedada en otros espacios:

[en los malones usábamos] la falda plato, que era amarilla, la blusita con beige o café, con motivo amarillo, así redondito, abrochadito en el hombro [que nos hacía] mi tía Carmen. (...) abajo usábamos calzones y enagua y los soquetes y zapatillas de gimnasia de lona o zapato de charol con argollitas. Lo que más me acuerdo yo es que me peinaban (...) me hacia esos teléfonos o nos hacíamos cola de caballo o nos hacíamos chapes. (...) Las mujeres adultas no ocupaban esos vestidos, los usaban las chicas. (...) (Rosario Casala, Buin, Santiago).

Más allá, la importancia del malón es triple: por una lado congrega a la mayoría de los que se perciben y autoperciben como jóvenes; por otro, construye en torno a la edad atribuciones y distinciones específicas, separadas de los espacios y bienes simbólicos visualizados como provenientes del mundo adulto y, por último y más importante, establece a partir de sus omisiones y elecciones de estos bienes culturales, la distancia y cercanía con las distintas sensibilidades juveniles presentes en la sociedad. Al contrario de las boites, en los malones el control de la música que se baila, los modos de organización y puesta en escena corren en manos de los propios actores, por tanto, se actualizan y cristalizan directamente los contenidos materiales y simbólicos que se creen pertenecientes al imaginario juvenil del momento y, aún más, que se sienten como pertenecientes al imaginario juvenil de un "nosotros", llave para entender las diferencias identitarias juveniles tanto a nivel interno como externo. El carácter cooperativo del malón vigoriza estos mecanismos, puesto que no sólo implica aportes en bebestibles y comestibles, sino que también la contribución de discos de vinilo para ser escuchados y bailados en la celebración, ello debido a la escasez de música juvenilizada en los hogares paternos.

Por otra parte, los malones suplen los limitados espacios de holganza y esparcimiento dirigidos a la interacción con el sexo opuesto y la propiciación de relaciones afectivas. Aunque controlados en horario y casi disciplinados -"No era cuestión de que nosotras anduviéramos sueltas por ahí y nadie nos viera. Estaba la dueña de casa. Yo creo que [había] bastante control, porque nos daban permiso hasta cierta hora" (Rosario Casala, Buin)-, estos espacios posibilitan el galanteo, el escarceo amoroso y el noviazgo informal: el "pololeo".

La rigidez moral y las estrictas prescripciones afectivas de antaño comienzan lentamente a caducar a partir de las experiencias de las nuevas 
generaciones. Debido a ello, la extensión e institucionalización del pololeo desde mediados del siglo XX es uno de los motores fundamentales de la juvenilización acontecida a nivel biográfico y es el dispositivo troncal que altera y ahonda la breve condición de soltero/a -propia de la sociedades rurales- para definir la condición sociocultural de "lo joven". Dicha relación prematrimonial entre pretendientes -antes duramente fiscalizada e, incluso, sancionada- amplía a edades mucho más prematuras y tardías la experimentación de la juventud por cuanto dicha relación no condiciona necesariamente la unión matrimonial y el consiguiente paso a la adultez en razón de la emancipación productiva y la reproducción. Pese a que el uso de medios anticonceptivos (píldoras y profilácticos) aún no debutan masivamente, la alternancia de mayores relaciones de noviazgo (no necesariamente extensos y sin implicaciones procreativas), terminan por extinguir la soltería como aglutinador identitario y episodio biográfico exclusivamente juvenil, sobre todo en las clases altas y medias urbanas. De esta manera, el matrimonio como corte liminar del -breve- tránsito juvenil de antaño, tiende a desaparecer como coordinador último y terminal de la condición del ser "joven". Aunque tolerado por el mundo adulto, el pololeo contiene una serie de disposiciones normativas consuetudinarias que regulan ritualmente su funcionamiento: desde el "pinchar" -cortejo y seducción-; pasando por la explicitación del vínculo -solicitud del muchacho a la joven y ésta a los padres para su aprobación-; hasta las actividades relacionales -físicas y sociales- permitidas.

\section{HIPÉRBOLES GENERACIONALES}

El polimorfismo de las y los jóvenes en este momento histórico, particularmente de Coléricos y Carlotos, y las modalidades materiales y simbólicas de la propia construcción de la condición juvenil, plantea problemas conceptuales y teóricos de cierta complejidad. Desde fines de la década de $1960 \mathrm{el}$ Center for the Contemporary Cultural Studies (CCCS) de Birmingham focaliza su atención en la primeras culturas juveniles surgidas en Inglaterra en la década de 1950. Sus referentes empíricos son precisamente agregaciones juveniles cercanas estilísticamente a las chilenas, para las cuales los investigadores de Birmingham proponen el concepto analítico de "subcultura", desplazando con ello las teorías biologicistas y desviacionistas y los postulados -muy en boga para la época- que reducen la existencia problemática de las culturas juveniles a un conflicto derivado de la "brecha" generacional sin atención a la clase social de pertenencia. De esta forma, y a través 
del concepto gramsciano de "hegemonía", una parte importante de las investigaciones compiladas en la obra colectiva de Hall y Jefferson (1976), conciben a estos colectivos -sus estilos y expresiones en la vida social y material-como formas de resistencia simbólica frente a la opresión de los sistemas de control impuestos por las clases dominantes. Debido a ello, la escenificación de la identidad es interpretada como un ritual contestatario y una solución "mágica" a los conflictos y contradicciones de clase "reales" que son representados por los jóvenes en el "teatro de la hegemonía" (Feixa, 1999: 75).

No obstante, Coléricos y Carlotos no sólo no se ajustan a la noción canónica y específica de "subcultura" acuñada por los autores de Birmingham, sino que exceden, asimismo, el concepto de "contracultura", nomenclatura utilizada para referirse a las culturas juveniles "alternativas" surgidas en las capas medias e ilustradas -como los beatniks y hippies-, cuyas prácticas identitarias se dirigen a articular una oposición a los valores institucionales dominantes, rompiendo la hegemonía cultural burguesa de manera directa por medio de la disidencia política, artística y moral (cf. Hall, 1970).

Las raíces mayoritariamente burguesas y mesocráticas de Coléricos y Carlotos no pueden homologarse a sus símiles europeos o norteamericanos de origen subalterno y raíz obrera. Su 'proyecto' contracultural es nulo y su constitución subcultural se limita, en su rebeldía embrionaria y más bien inocua, a una reivindicación de la nombradía y condición juvenil. Su "resistencia", en los casos más radicalizados, no se dirige a la reproducción de las relaciones de clase existentes, sino a lo sumo a la perpetuación de las relaciones intergeneracionales dominantes. Una disputa situada más bien en la cultura parental que oscila, como plantea Cohen (1980), entre la necesidad de crear y expresar la autonomía y la diferencia respecto a los padres y la necesidad de mantener las identificaciones con ellos. La escenificación de su identidad en torno a la masculinidad, por ejemplo, expresa este vaivén: un simulacro de rebeldía contra la dominación parental que no supone subvertir en modo alguno el orden y fundamento de las relaciones intergenéricas -y de subordinación- en la constitución de la familia patriarcal. Más aún, las prácticas cotidianas entre sus pares robustecen dicho orden, al constituirse como ensayos de la vida adulta: clasismo, autoritarismo y sexismo.

Debido a ello, sostenemos que estas primeras culturas juveniles son fundamentalmente "conexiones generacionales" y, en mucho menor medida, "unidades generacionales autoconscientes" (Mannheim, 1990). Resulta claro, en nuestro caso, que una parte importante de las narrativas biográficas 
presentan esta conexión generacional en la medida que gran parte de las transformaciones en la cultura parental -la expansión del 'pololeo' y la mutación de la soltería, por ejemplo-, las nuevas prácticas de sociabilidad situadas en los espacios intersticiales de la vida institucional, y el impacto del desarrollo de una industria cultural segmentada tienen un correlato en la "estratificación de la experiencia", lo que los vincula de una manera amplia, por cuanto son coordenadas generales donde transita un modo común de construir la condición juvenil. Sin embargo, los materiales específicos de elaboración de esta condición tienen variantes sustantivas, relativas a la posición de clase, género y territorio. Las narrativas biográficas femeninas, por ejemplo, presentan procesos de experimentación juvenil más restringidas en relación a la de los varones debido a una dependencia, vigilancia y control parental más acusado y a las limitaciones en el acceso a espacios y tiempos juvenilizados. Lo mismo sucede con algunos sujetos situados en las capas medias y populares, o situados territorialmente distantes de los nodos de diseminación de los bienes culturales segmentados, para los cuales la condición juvenil aparece ya como un privilegio, ya como una fase abreviada y ligada a los tiempos liminares de la educación formal.

Estas condiciones y variantes evidencian, igualmente, la presencia de identidades generacionales más intensas, aunque minoritarias. La existencia de una "unidad generacional autoconsciente", que manifiestan algunos Coléricos más radicalizados -como los Carlotos-, expresa la importancia mayor que estos colectivos le dan al marcador juvenil, puesto que los sujetos se reconocen e identifican con los contenidos y referentes asignados por el grupo a ese determinado estadio en la biografía. La articulación de estas unidades tiene correlatos y contenidos específicos -como la espectacularización y mediatización del estilo y las prácticas sociales asociadas a ello-, pero encuentran limitaciones materiales y simbólicas -como las morales y valóricas- que terminan difuminando y atenuando elaboraciones identitarias más intensas que posibiliten la formación y extensión de "grupos concretos" (Mannheim, 1990) en la propia sociedad mayor.

Pese a ello, la génesis extensiva de conexiones generacionales surgidas en Chile desde la segunda mitad de la década de 1950 expresa un hecho cardinal: las alteraciones en los modos de producción de individuos, que se acompañan del mismo habitus (Bourdieu, 1988). En este sentido, los cambios en las condiciones de reproducción materiales y sociales en Chile producen agentes inéditos en vastos sectores de la sociedad chilena. Si bien es cierto que las expresiones más radicales se concentran en una porción menor de las narrativas biográficas de las y los jóvenes indagados y la cons- 
trucción social de la desviación por parte de las instituciones mediáticas conllevan a su sobrerrepresentación, Coléricos y, particularmente, Carlotos emergen como una metáfora exagerada -una hipérbole- del cambio social.

Unos años más tarde -entrada ya la década de los '60- esta hipérbole calibrará sus referentes, debido a que estas primeras culturas juveniles conectadas generacionalmente darán paso a la proliferación de unidades generacionales autoconscientes y grupos concretos diversificados con un soporte identitario - definiciones y fronteras simbólicas- de mayor espesor. Coléricos y Carlotos, son de este modo, una cabeza de playa que logra comunicar y construir arquetipos juveniles a ser observados y apropiados por otros jóvenes, lo que les da continuidad a estas emergentes culturas juveniles. Hacia 1961, la revista Ercilla abre un reportaje al balneario de Cartagena con los siguientes párrafos:

(...) Los que creen que los "James Dean" y los "casacas negras" sólo existen en la pantalla, se llevarán duras sorpresas si van a Cartagena. Allá no son grupitos, sino casi todos los muchachos los que llevan las tenidas "semillas de maldad". Afortunadamente, muchos sólo se quedan en la imitación de la vestimenta y los gestos, aunque grupos de "carlotos" (así los llama la gente) intentaron destruir electrolas, donde alguien, inocentemente, quiso interrumpir una serie de rocks y colocó una canción mexicana. (...) La tenida "James Dean" es barata, y, además, cómoda: Blue-jeans, casaca o gruesos sweaters, pelo crecido (ahorro en peluquería). Tal vez lo único imperdonable es su afición al rock. Siete u ocho parlantes de locales diferentes, a lo largo de su bella terraza costanera, hacen de Cartagena un infierno de alaridos y ritmos para gimnastas, que tienen ancha acogida. (...) Entre ese ejército de "carlotos" ingenuos (“¿qué les hemos ofrecido aparte de rock?" se preguntó un papá), también se cuelan pandillas auténticas (...). (Ercilla, miércoles 1 de marzo de 1961, p. 12).

\section{REFERENCIAS}

Ahumada, Jorge 1958. En vez de la miseria. Santiago: Editorial del Pacífico.

Boëthius, Ulf. 1995. "Youth, the media and moral panics". In Förnas, Johan \& Göran Bolin (eds.) Youth Culture in Late Modernity, pp. 39-57. London: Sage.

Bourdieu, Pierre. 1988. La distinción. Madrid: Taurus.

Brunner, José Joaquín. 1988. Un espejo trizado. Santiago: FLACSO.

Brunner, José Joaquín; Barrios, Alicia; Catalán, Carlos. 1989. Chile: Transformaciones culturales y modernidad. Santiago: FLACSO.

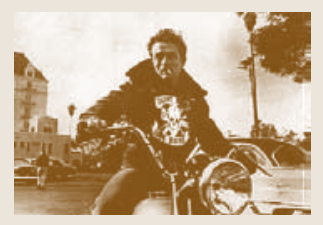

\footnotetext{
maciones culturales y modernidad. Santiago: HLACSO.
} 
Caccia-Bava, Augusto; Feixa, Carles y González, Yanko. 2004. Jovens na América Latina. Sao Paulo: Escrituras.

Clarín [periódico]. 1959. "Se entregó el carloto protegido por patota de matones y motonetistas". Martes 21 de abril, pp. 1-3.

Clarín [periódico]. 1959. "Canallesca declaración de Boassic 'Mariluz se mató por secreto pecado"”. Miércoles 22 de abril, pp. 1-3.

Cohen, Phil. 1980. "Subcultural conflict and the working-class comunity". In Stuart Hall, Dorothy Hobson, Andrew Lowe and Paul Willis (eds.), Culture. Media, lenguaje. London: Hutchinson University Library.

Cohen, Stanley. 2002. Folk Devils and Moral Panics. The Creation of the Mods and Rockers. London: Routledge.

Clarke, John. 1976. "Style". In Stuart Hall, and Jefferson Tony (eds.), Resistance throug Rituals. Youth Subculture in Post-War Britain. London: Hutchinson University Library.

Correa, Sofía; Figueroa, Consuelo; Jocelyn-Holt, Alfredo; Rolle, Claudio y Vicuña, Manuel. 2001. Historia del siglo XX chileno. Santiago: Sudamericana.

Correo de Valdivia [periódico]. 1959. “¿Jóvenes Coléricos?”. Miércoles, 29 de abril, p. 3.

Cross, Robert. 1998. "The Teddy Boy as Scapegoat”, Doshisha Studies in Language and Culture 1-2: pp. 263-291.

Doherty, Thomas. 2002. Teenagers and Teenpics The Juvenilization of American Movies in the 1950s. Philadelphia: Temple University Press.

Ecran [revista]. 1957. "Doroteo Marti llegará a fines de marzo". Martes 19 de noviembre, p. 21.

Ercilla [revista]. 1959. "William Reb y sus Rock King en radio Minería”. Miércoles 29 de abril, pp. 17-18.

Ercilla [revista]. 1959. "La versión del acusado: Fue una chacota que resultó fatal”. Miércoles 6 de mayo, pp. 8-9.

Ercilla [revista]. 1959. "Una generación en la encrucijada”. 29 de abril, p. 16.

Ercilla [revista]. 1961. "Cartagena por dentro. Arena, huevitos duros y rock and roll”. Miércoles 1 de marzo, pp. 12-13.

Erikson, Erik. 1950. Childhood and Society. New York: Norton.

Feixa, Carles. 1999. De jóvenes, bandas y tribus. Barcelona: Ariel.

Feixa, Carles y González, Yanko. 2005. 'The Socio-Cultural Construction of Youth in Latin America: Achievements and Failures'. In Helena Helve y Gunilla Holm (eds.), Contemporary Youth Research: Local Expressions and Global Connections, pp. 39-48. Londres: Ashgate.

García Canclini, Néstor. 1990. Culturas híbridas. Estrategias para entrar y salir de la modernidad. México: Grijalbo.

González, Yanko. 2004a. Óxidos de identidad: Memoria y juventud rural en el sur de Chile (1935-2003). Tesis Doctoral. Barcelona: Universidad Autónoma de Barcelona.

González, Yanko. 2004b. “Existieron una vez sesenta y dos muchachos: Parami- 
litarización y militancia de las juventudes mesocráticas chilenas", JOVENes, Revista de Estudios sobre Juventud 19, pp. 82-115.

Gurrieri, Adolfo; Torres-Rivas, Edelberto; González, Janette y De la Vega, Elio. 1971. Estudios sobre la juventud marginal latinoamericana. México: Siglo Veintiuno Editores/Editorial Universitaria.

Hall, Stuart. 1970. Los hippies: una contra-cultura. Barcelona: Anagrama.

Hall, Stuart \& Jefferson, Tony (eds.). 1976. Resistance throug Rituals. Youth Subculture in Post-War Britain. Londres: Hutchinson.

Hebdige, Dick. 2004/1979. Subculture: The Meaning of style. Londres: Routledge.

Hermann, Kai. 1968. Los estudiantes en rebeldía. Madrid: Rialp.

I.N.E. (Instituto Nacional de Estadísticas). 1999. Estadísticas de Chile en el siglo $X X$. Santiago: Instituto Nacional de Estadísticas.

La Cuarta [periódico]. 2003. "Cáncer se llevó al "Carloto", el James Dean chileno de los '50". Sábado 30 de agosto http://lacuarta.cl/ diario/2003/08/30/30.05.4a.CRO.CARLOTO.html [Visitada el 10 de enero de 2009].

La Cuarta [periódico]. 2006. “El 'Carloto' y la extraña muerte de su polola María Luz Tamargo”. Miércoles 19 de julio http://www.lacuarta.cl/ diario/2006/07/19/19.06.4a.CRO.CRIMEN.html [Visitada el 10 de enero de 2009].

La Tercera [periódico]. 1959. “Carloto”. Viernes 17 de abril, p. 2.

La Segunda [periódico]. 1959. "Dos certificados en pugna en el caso de la colegiala”. Miércoles 29 de abril, p. 16.

Mannheim, Karl. 1990. Le problème des générations. París: Nathan.

Mattelart, Michelle y Mattelart, Armand. 1970. Juventud chilena, rebeldía y conformismo. Santiago: Universitaria.

Mead, Margaret. 1990. Cultura y compromiso. Barcelona: Gedisa.

Monod, Jean. 2002. Los barjots. Etnología de las bandas juveniles. Barcelona: Ariel.

Montalva, Pía. 2004. Morir un poco. Moda y sociedad en Chile. 1960-1976. Santiago: Editorial Sudamericana.

Morales Pettorino, Félix. 2006. Nuevo diccionario ejemplificado de chilenismos. Valparaíso: Puntángeles / Universidad de Playa Ancha.

Parsons, Talcott. 1963. "Youth in the context on American Society". In Erik Erikson (ed.). Youth, change and challenge, pp. 93-119. New York: Basik Books.

Ponce, Aníbal. 1939. Ambición y angustia de los adolescentes. Buenos Aires: Talleres Gráficos L. J. Rosso. 1960/1938. Psicología de la adolescencia. México: Manuales UTEHA Unión Editorial Tipográfica Hispanoamericana.

Ponce, David. 2008. Prueba de sonido. Primeras historias del rock en Chile (19561984). Santiago: Ediciones B. 
Salas, Fabio. 2003. La primavera terrestre. Cartografía del rock chileno y la Nueva Canción Chilena. Santiago: Cuarto Propio.

Salazar, Gabriel y Pinto, Julio. 2002. Historia contemporánea de Chile, tomo V: Niñez y juventud. Santiago: Lom.

Solé, Jordi. 2006. "El naixement de la cultura juvenil a través del cinema”. Temps d'Educació 31, pp. 163-178.

Thornton, Sarah. 1995. Music, Media and Subcultural Capital. London: Routledge.

Vea [revista]. 1959. "Cosecha de sangre de mala semilla”. Jueves 23 de abril, pp. 16-17.

Vea [revista]. 1959. "Cara y Cruz en el caso Boassi”. Jueves 7 de mayo, pp. 1617.

Zarzuri, Raúl y Ganter, Rodrigo (eds.). 2005. Jóvenes: la diferencia como consigna. Santiago: CESC. 